\title{
Research on Networked Development of Physical Education
}

\author{
Xu Hailong \\ Wushu Department \\ Hebei Sport University \\ Shijiazhuang, China \\ xuhailonghebei@yahoo.com.cn
}

\author{
Liu Yingqi \\ Wushu Department \\ Hebei Sport University \\ Shijiazhuang, China \\ xuhailonghebei@yahoo.com.cn
}

\author{
$\mathrm{Ma} \mathrm{Na}$ \\ Wushu Department \\ Hebei Sport University \\ Shijiazhuang, China \\ xuhailonghebei@yahoo.com.cn
}

\begin{abstract}
The original meaning of sports education is to teach by physical exercise, in English it can be say as "physical education". But with the development of sports, the connotation of modern sports has completed its transition from education and bodybuilding to physical culture, which has expanded the function and scope of sports. Therefore, modern physical education is not just physical education at school, which needs the physical educators and sports enthusiasts to renew their physical knowledge and to know and strengthen the continuing education, in this way they will know the necessity and feasibility of developing the network education for physical education.
\end{abstract}

\section{Key words- Physical education; Network; development}

\section{THE HISTORICAL BACKGROUND FOR DEVELOPING MODERN DisTANCE PHYSICAL EDUCATION}

At present the online universities are on the rise around the world, many prestigious universities, such as Stanford University, Columbia University, Duke University, have opened the online course. Basing on the survey report of America, in the next few years, about $75 \%$ of the universities in America will provide network education, and 58000 thousand people are willing to accept online courses, and the online education may feed the thirst for knowledge of considerable groups. As Robert MacLin, the director of Research Institute for Study of Columbia University had ever said: "the Internet has opened a new learning world."

Now the network education for physical education is still in blank space state, particularly there still has a large market to be explored for continuing education and renewing knowledge of these physical educators, which provide precondition and solid foundation for establishing distance education. Taking the China Sport Science Society for example, about every year there will be 15 national wide academic events, including academic conference, seminar and subject training class, every time it demands a lot of manpower and material resources. So imagine that if we change this way and put the conference and training into the Internet, then the participator will greatly increase, cost will be reduced and the quality will be improved, meanwhile, the events will free from the limit of time and space. And the only essential condition for this is to turn the Internet education into universal education.

The development of Chinese distance education has made the sports bring forward requirements for modern distance education, which should serve for the physical education by virtue of imagine and network tools. Admittedly, the physical education is different from others cultural curriculums, it has some technical problems. In the traditional concept, "education" is regarded as an independent social category; "communication" is another independent social category; and "computer network" is also a different category. But actually, the limitation among these categories is disappearing increasingly, the learning style of breaking through the limit of time and space has promoted the development of education, and it will certainly promote the update of physical education pattern.

\section{A. Emergence and Development of Chinese Distance Education}

Australia distance education expert Latebem (1999) has pointed out in his thesis that seeing from the Chinese Imperial Examination System we may know that the history of open learning and self-study of knowledge and wisdom in China has more than 1300 years, the largest scale and system in the history of distance education is the Radio and Television University which emerged in the early 1980s. China is a country with large population, so we need strive to develop education and distance education in order to turn population burden into talent resources, which will have profound impact on Chinese education reform.

\section{B. Realization of Modern Distance Physical Education is the Content of Education Reform}

The distance education has broken the influence of region and time on the spread of education. The new educational objective, in the final analysis, is to realize and develop the mass education in the existing environment. The modern distance education marked by network is carrying out the rule of optimization selection on the enclosed traditional school-running pattern, that is to say a system which provides convenient, fast and high quality distance education will finally go the path of maturity and development.

The education and sports will finally turn into a special industry in the knowledge-based economy society and play a large role in society. They are not only the mainstay of the human resources development in society, but the key of adjustment and reform of social industrial structure. Actually, the modern distance education around the world has developed beyond the limits of human imagination, the network primary school, secondary school and university structuring on networked electronic platform is forming increasingly. 


\section{Lead Physical Education towards Modern Distance Education}

Sports are deeded as one of the fastest fields of information update. We can know accurately situation of teaching at home and abroad and present all kinds of audiovisual materials as well as textual and graphic files to students in time by networked interactive teaching. The selfdevelopment tendency of physical education determines that quite part of updating content needs digital interactive dynamic demonstration teaching, which can not be completed by traditional teaching method.

\section{Mean of Distance Education Helps to Promote the Reform and Development of Sports}

Modern distance physical education is supported by modern information technology, so its development will certainly drive the development of China information industry. At the same time, we need try to develop the distance physical education in the light of market mechanism and the ideal of industrialization, carry forward the healthy and orderly development of distance physical education and physical industry in China, and to promote the real achievement of "National Fitness Program”.

\section{CONCEIVE AND FRAMEWORK OF TURNING PHYSICAL EDUCATION INTO MODERN DISTANCE EDUCATION}

\section{A. Modern Distance Physical Education System}

Modern distance physical education system can be constituted from the following patterns:

1) Real time teaching system: Radio television system, video conference system. Its characteristics lie in: visual in image, high efficiency, and teachers and students may have real time interactive discussion online.

2) Nonsynchronous learning system: heterochronous interaction between teachers and students.

3) Cooperative learning system: The students themselves or among students may evaluate or discuss online through the website, which emphasize the discovery learning of independent exploration.

\section{B. Physical Education Network Teaching System}

Network teaching system is kind of system software which provides distance teaching service, it organically integrates the network course with distance teaching of school, including the System of Information Communication, Multi-Media Courses Learning System, System for Counseling and Answering Questions and System for Checking and Evaluating, etc.

\section{System of Physical Education Network Teaching Information Resources}

The system of physical education network teaching information resources includes: Data Bank of Subject Document, Subject Question Bank, Subject Media Material Database, Subject Courseware Database, Technology Exercising Database and Exercise Prescription Database, etc.

\section{Management System of Modern Distance Physical Education}

Management system of modern distance physical education is used for the systematic management of physical education network teaching resources and establishing a unified physical teaching database, which may provide powerful information support for making all kinds of physical education network courseware and teaching. It includes Distance Teaching Management System, Course Learning Management System, Teaching and Learning System, Examination Management System, Referral Information System, Data Statistics and Analysis System, Fitness and Health Monitoring System and Sport Technique Evaluation System, etc.

\section{E. Development System of Physical Education Network Courses}

The development of network courseware is a new pattern of lesson preparation, with the design tool of network courseware and under the support of correspondent database it can meet the requirements of rapid generating of multimedia courseware, transplantation and interaction, including Development Tool of Network Courseware, Multimedia Network Course Resources and Template Base of Network Course Development, etc.

\section{F. Characteristics of Network Courses in Distance Physical Education}

Network course is the summation of the content of certain subject and its implementation of teaching activities through the network, and it can be divided into two parts: content of course organized in light of definite teaching objectives and instructional strategies and supporting environment of web-based teaching. It has the following characteristics:

1) Advanced nature

The advanced content and teaching system reflect the development direction and the stamp of age of physical education discipline.

2) Open

Excellent capacity of network information, gym teachers may produce network teaching scheme depending on their on their own characteristics, the production and application of network course has the characteristic of automation, large-scale, industrialization and strong expandability.

3) Interactivity

Education is not equal to publicity, so the information flow shall be bidirectional.

\section{4) Sharing}

It can be realized whether in wide area network, local area network or stand-alone and adapt to the visit of different terminal equipments (such as PC, information household appliances). It demands that in the process of implementation of distance education, the various media shall be published synchronously, which contributes to the selectivity for users, reutilization of teaching materials, resources sharing and is easy to extension. 


\section{5) Cooperation}

It can be used not only for the communication between teachers and students, but for the mutual interaction among students.

6) Independency

Reflecting the educational thought centered on students and emphasizing self-directed learning and individualized learning,

7) Vitality

The application of various multimedia authoring tools, such as the animation and video technologies like $3 D$ max studio, Adobe Premier, Flash and Java, etc., which make the courseware and webpage more vivid and lively.

\section{G. Application Environment for Realizing the Physical Education Network Courses}

1) Complete the structure chart of topology (the stereo type of sheet, starlike and blend shape) for the platform of distance physical education;

2) Establish the NOC (Network Operation Center) and NMS (Network Management System) applicable for distance physical education and attach great importance to expandability.

3) Establish technical training center of physical distance teaching, cultivate modern distance educator and take charge of update of related knowledge.

It is worth noting that, different from the digitization and networking of traditional physical education, distance physical education relies on the teaching supporting platform to implement activities and its ultimate goal it to support multiple model of teaching.

III. FEASIBILITY ANALYSIS FOR TURNING PHYSICAL EDUCATION INTO MODERN DISTANCE EDUCATION

With the repaid development of Internet and Information Industry throughout the world, it is feasible for the implementation of distance education on the Internet platform. In our country, many high-level first-class universities have opened network education institute in recent years. They have effectively communicated educational resources with high speed to the computer terminals of every student by server connected to high speed optical fiber. Besides they have built the online platform for reasonable teaching and student management, and supported by realistic teaching school in various regions at the same time, which have made a dynamic integration of network education and realistic traditional education. In practice it has been proved that we may receive good effect from network education.

However, the network education in the colleges of our country is only confined to these famous-brand majors and only these "Book Major" with strong theoretical knowledge, such as the major of arts and science, and there has no network education in the field of physical education. Therefore, it is really necessary, realistic and feasible way for the training of sports talents in our country to build hardware and software platform and development distance education of physical education basing on the experience of other majors, which have developed the network education.

\section{CONCLUSIONS}

With the extensive use of virtue really technology, the distance physical education has improved the network education from two-dimensional image to a new level, that is, the complete environment of control person threedimensional space. Thus the traditional model of teaching will disappear gradually and the training feedback system consists of portable computer and the sensor connected to one's body may guide students' technical moves accurately, and transfer the optimum technical conditions that meet the physical characteristics of students. Students may obtain the guidance from many aspects, such as exercise training, sport nutrition, and exercise prescription by the timely feedback from network, and send message alternatively by the Internet.

\section{REFERENCES}

[1] Li Xiaoyan. Cause and Countermeasures of Unbalanced Regional Development in China [J]. Journal of Zhengzhou Institute of Aeronautical Industry Management (Edition of Social Science), 2008, (4).

[2] Song Minghua. A Comparative Study of Higher Education's Contributions to Economic Growth Rate of East Part and Middlewest Part of China [J]. Social Science, 2005, (7).

[3] Wang Kaishou. Study on Current Situation on Network Teaching of Physical Education in Colleges and its Development Countermeasures [J]. Journal of Chengdu Sport University, 2006, (04). 